ERNST

BERELEY NATIGNAL LAB⿴RATIRY

६.

Plasma Synthesis of High Temperature Ceramic Films

Ian G. Brown and Othon R. Monteiro

PECEIVED

Accelerator and Fusion

Research Division

APR 131999

O T I

November 1998

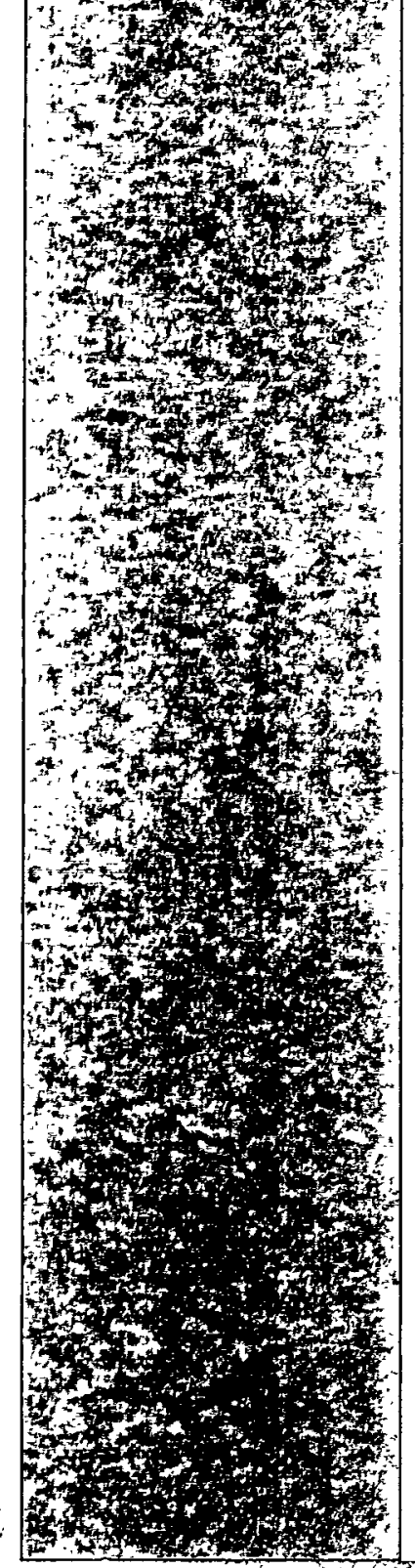


This report has been reproduced directly from the best available copy.

Available to DOE and DOE contractors from the Office of Scientific and Technical Information, P.O. Box 62, OakRidge, TN 37831; prices available from (423) 576-8401.

Available to the public from the National Technical Information Service, U.S. Department of Commerce, 5285 Port Royal Rd., Springfield, VA 22161.

This report was prepared as an account of wrork sponsored by an agency of the United States Government. Neither the United States Government nor any agency thereof, nor any of their employees, makes any warranty, expressed or implied, or assumes any legal liability or responsibility for the accuracy, completeness, or usefulness of any information, apparatus, product, or process disclosed, or represents that its use would not infringe privately owned rights. Reference herein to any speisific commercial product, process, or service by trade name, trademark, manufacturer, or otherwise, does not necessarily constitute or imply its endorsement, recommendation, or favoring by the United States Government or any agency thereof. The views and opinions of authors expressed herein do not necessarily state or reflect those of the United States Government or any agency thereof. 


\section{DISCLAIMER}

Portions of this document may be illegible in electronic image products. Images are produced from the best available original document. 
LBNL-42492

ORNL/Sub/94-SS109/03

\section{PLASMA SYNTHESIS OF HIGH TEMPERATURE CERAMIC FILMS*}

November 1998

Research sponsored by the U.S. Department of Energy Office of Fossil Energy

Advanced Research and Technology Development Materials Program

Report Prepared by

Ian G. Brown and Othon R. Monteiro

Ernest Orlando Lawrence Berkeley National Laboratory

University of California, Berkeley, CA 94720 under

ORNL/Sub/94-SS109/03

for

OAK RIDGE NATIONAL LABORATORY

Oak Ridge, Tennessee 37831

Managed by

LOCKHEED MARTIN ENERGY RESEARCH CORP.

for the

U.S. DEPARTMENT OF ENERGY

under contract DE-AC05-96OR22464

*This work was supported by the U.S. Department of Energy under Contract Number DE-AC03-76SF00098. 


\title{
PLASMA SYNTHESIS OF HIGH TEMPERATURE CERAMIC FILMS
}

\author{
Ian G. Brown and Othon R. Monteiro \\ Lawrence Berkeley National Laboratory \\ University of California \\ Berkeley, CA 94720
}

FINAL REPORT

\begin{abstract}
Thin films of alumina, chromia, mullite, yttria and zirconia have been synthesized using a plasma-based method called metal plasma immersion ion implantation and deposition (Mepiiid) - a highly versatile plasma deposition technique with ion energy control. Monolithic films (a single ceramic component) and multilayer films (individual layers of different ceramic materials) were formed. The films were characterized for their composition and structure in a number of different ways, and the high temperature performance of the films was explored, particularly for their ability to maintain their integrity and adhesion when subjected to repetitive high temperature thermal cycling up $1100^{\circ} \mathrm{C}$. We found that the films retain their adhesion and quality without any apparent degradation with time, even after a large number of cycles; (the tests were extended out to a total of 40 cycles each of 24 hours duration). After repetitive high temperature thermal cycling, the film-substrate adhesion was greater than $\sim 70 \mathrm{Mpa}$, the instrumental limit of measurement, and the interface toughness was approximately $0.8 \mathrm{MPa} \mathrm{m}^{1 / 2}$.
\end{abstract}

Research supported by the U.S. Department of Energy, under the Fossil Energy Advanced Research and Technology Development Materials Program, Subcontract Number ORNL/Sub/94-SS109/03, and under Contract Number DE-AC03-76SF00098. 
PLASMA SYNTHESIS OF HIGH TEMPERATURE CERAMIC FILMS

FINAL REPORT

\section{Contents}

Page

1. Introduction 3

2. Outline of the Plasma Synthesis Technique 4

3. Experimental Results 6

3.1 Alumina and Chromia 6

3.2 Mullite $\quad 7$

3.3 Yttria and Zirconia 11

4. Conclusions 13

$\begin{array}{ll}\text { Acknowledgments } & 14\end{array}$

$\begin{array}{ll}\text { References } & 15\end{array}$

$\begin{array}{lr}\text { Figures } & 18\end{array}$ 


\section{PLASMA SYNTHESIS OF HIGH TEMPERATURE CERAMIC FILMS}

\section{INTRODUCTION}

Thin films can be formed by a wide variety of plasma methods [1]. We have developed a plasma-based thin film deposition technique with the important feature that the energy of the depositing ion flux can be controlled over a wide range. Highly adherent, fully-dense films of metals, alloys (including non-equilibrium alloys) and other conducting materials, and their oxides and nitrides, can be formed. In the early stages of the process the ion energy is held in the $\mathrm{keV}$ range so as to produce atomic mixing at the film-substrate interface, and in the latter stages of deposition the energy is reduced so as to optimize the film structure and morphology.

The technique draws upon previously existing technology to form a new plasma-based film synthesis approach that is a hybrid of several more commonly know methods, including filtered cathodic arc deposition [2-4], ion beam assisted deposition (IBAD) [5-8], ion beam mixing [57,9], and plasma immersion ion implantation (piii) [10,11]. In our method, which we've dubbed Mepiiid (Metal plasma immersion ion implantation and deposition), the object to be implanted is immersed in a metal plasma of the desired species and repetitively pulse-biased to an appropriately selected negative voltage [12-16]. A high voltage sheath rapidly forms at the substrate-plasma boundary, and plasma ions are accelerated through the sheath and into the substrate, thereby accomplishing implantation into the substrate of plasma ions at an energy determined by the bias voltage. Because of the surface retention of condensed metal plasma, the process in a metal plasma is quite different from in a gaseous plasma. Ions that are deposited during the pulse-off part of the cycle are deposited on the surface as a sub-monolayer film, and ions that are accelerated from the plasma and bombarded into the substrate during the high voltage bias part of the cycle are energetically implanted; energetic ion collisions with previously-deposited neutral metal atoms also produce recoil implantation. By varying the proportions of the direct and recoil implantation (ie, the duty cycle of the pulse biasing) one can tailor the shape of the implantation depth profile, and the range can be tailored by the amplitude of the applied pulse voltage. The whole operation can be time-varied throughout the processing duration, starting for example with a high energy phase so as to create a deep buried layer of the implanted species (an ion mixing phase) and slowly changing to a low energy phase whereby the surface film is built up by plasma deposition (an ion beam assisted deposition phase). By controlling the plasma ion energy we thus acquire control over two very important features of the deposition process - the interface width can be tailored, and the film morphology and structure can be controlled. In this way one can synthesize a surface film of precisely controllable thickness having a well-determined and controllable atomically mixed interface with the substrate, and the parameters of the film and the interface can be tailored over a wide range. For purely metallic films, the process is carried out at a vacuum in the $10^{-6}$ Torr range. Oxides and nitrides can be formed by doing the deposition at the appropriate background pressure of oxygen or nitrogen, typically a few tens of microns. 
In our plasma materials synthesis research program we have shown that highly adherent, high quality films of many different kinds of materials can be formed in this way, including films of metals [17-19], metal oxides [20-21] and oxide ceramics [22-25], optoelectronic materials [26], high- $T_{c}$ superconductors [27,28], diamond-like carbon [29-31], and multilayer structures with complex structure [32-34]. Concise reviews have been presented of the method and applications $[35,36]$. We point out that our film synthesis technique - Mepiiid - is a research tool that we have developed in our laboratory; it is not a commercialized technology, nor has its application yet been significantly taken up at other laboratories.

Here we report on our experimental investigations of the application of these methods for the formation of high temperature ceramic films. We have formed films of alumina, chromia, mullite $\left(3 \mathrm{Al}_{2} \mathrm{O}_{3} \cdot 2 \mathrm{SiO}_{2}\right)$, zirconia and yttria. Film structures investigated were monolithic (a single ceramic composition throughout the film), multilayer (layers of different ceramic materials together forming a composite film), graded (the interfaces between different regions of the film being atomically mixed for an extended range), and doped (small amounts of a dopant species added to the main film material). For the most part, the substrate material used was silicon carbide. The films were characterized in a number of ways including for composition and structure, and for adhesion to the substrate especially subsequent to repeated high temperature thermal cycling. (The films were not tested for their performance in the presence of alkali metal salts). In the following we firstly summarize the plasma synthesis technique as applied for the present purpose, and then present the characterization and performance results obtained for the different kinds of films.

\section{OUTLINE OF THE PLASMA SYNTHESIS TECHNIOUE}

The basic synthesis approach involves "immersion" of the substrate in the dense metal plasma formed by one or more vacuum arc plasma guns while controlling the energy of the depositing ions by the application of a high-frequency, repetitively-pulsed bias voltage to the substrate during the plasma deposition. Oxygen is added to the processing chamber at a suitably low pressure and is incorporated into the growing film primarily by surface oxidation and subsequent recoil implantation. Ion energy is controlled as a function of time, and the film-substrate interface can be tailored and the film structure optimized by the ion beam assist that is inherent to the process.

The vacuum arc is a high current discharge between two electrodes in vacuum in which highly ionized metal plasma is produced in abundance [2,37-39]. We have made several different embodiments of vacuum arc plasma gun [40]. For the work described here we used small, repetitively-pulsed versions typically operated at a pulse length of $5 \mathrm{~ms}$ and repetition rate of 1 or 2 pulses per second, and with arc current about $300 \mathrm{~A}$. Along with the metal plasma that is generated, a flux of macroscopic droplets (resolidified cathode debris) of size in the range 0.1 10 microns is also produced $[37,41,42]$. In general it is desirable to remove the solid particulate contamination and this can be done by using a curved magnetic duct (bent solenoid of magnetic 
field strength a few hundred gauss) which stops line-of-sight transmission of macroparticles while allowing the transport of plasma [43-45]. The overall plasma generation system thus consists of the repetitively pulsed plasma gun in conjunction with a $90^{\circ}$ magnetic filter.

Metal oxides can be formed by carrying out the deposition not in a high vacuum environment but in a somewhat higher pressure ambient of oxygen gas; we have found empirically that a pressure in the range $1-100 \mathrm{mTorr}$ is suitable for most purposes. In the present work the oxygen background pressure was 5 to $25 \mathrm{mTorr}$. The oxygen reacts at the freshly-deposited metallic surface (of thickness of order one to several monolayers for each $5 \mathrm{~ms}$ pulse of the plasma gun) to form a metal oxide, and a near-stoichiometric film can be formed.

Ion energy of the depositing plasma flux is controlled by repetitively pulse biasing the substrate. The pulse duration is $\sim 2-10 \mu$ s and the duty cycle $\sim 10-50 \%$. Pulsing the bias is necessary (for all but the lowest bias voltages) because a high-voltage dc bias would cause a discharge between the substrate and the vessel or the plasma gun; the plasma would be grossly perturbed. The solution is to switch off the bias before a discharge can occur (to limit the sheath expansion to modest distances), let the plasma recover, and then repeat the process; ie, to do the biasing in a repetitively pulsed mode. For the early stages of the deposition the pulse bias is held at a relatively high voltage of $-2.2 \mathrm{kV}$. For an aluminum plasma, the mean ion energy is then $3.75 \mathrm{keV}$, because the mean ion charge state of the aluminum plasma is 1.7 and $\mathrm{E}_{\mathrm{i}}=\mathrm{QV}$; for a silicon plasma the mean charge state is 1.4 and the mean ion energy is $3.1 \mathrm{keV}$; (the charge state spectra of vacuum arc produced plasmas have been discussed in detail in refs. 46,47). At this energy ions are implanted into the substrate to a depth of up to $100 \AA$. The film thus grows on the substrate from a highly mixed interface. When a film thickness of a few tens of angstroms has accumulated, the bias voltage is reduced, since intermixing with the substrate is no longer a factor and the higher ion energy would sputter away the already-deposited film. Moreover, it is known from a large body of work on ion assisted deposition that a modest ion energy can be advantageous for controlling characteristics such as the density, morphology and structure of the film. For the bulk of the plasma deposition process the pulse amplitude is kept at -200 volts.

To deposit films containing several different metallic elements we combine the operation of two plasma sources, with their magnetic ducts, so that plasma streams of different elements are mixed together before reaching the substrate. Optionally, a short magnetic multipole "plasma homogenizer" structure can be used also, to better blend the two plasmas and to produce a more uniform plasma density profile; we have incorporated this feature in some of our work [48]. The deposition can be carried out synchronously or asynchronously, i.e. the plasma sources can be operated simultaneously or sequentially, so as to form, for example, monolithic films that are a homogenous mixture of the oxided plasma species, or multilayers of the two oxides, or other more complicated structures. A schematic diagram of the dual-plasma deposition apparatus is shown in Figure 1. 


\section{EXPERIMENTAL RESULTS}

Our experiments are comprised of three more-or-less independent, though closely related, areas of investigation: (i) Synthesis and characterization of alumina films formed on iron aluminide and silicon carbide substrates; we also formed chromia films, but most of the analysis and characterization was done with alumina. (ii) Mullite $\left(3 \mathrm{Al}_{2} \mathrm{O}_{3} \cdot 2 \mathrm{SiO}_{2}\right)$ and mullite-like (aluminasilica films with composition ratios other than the $3: 2$ of mullite) films were made and fully characterized, also on silicon carbide substrate material. (iii) Yttria-zirconia films of two different kinds were formed, one with alternating layers of yttria and zirconia (multilayer films), and the second with mixed yttria and zirconia (monolithic films). These three areas of investigation are described in the following.

\subsection{ALUMINA}

The substrates used were small coupons of either silicon carbide or iron aluminide. The polished silicon carbide coupons were $0.5^{\prime \prime} \times 0.5^{\prime \prime}$ square and $0.1^{\prime \prime}$ thick, and the iron aluminide coupons, supplied by ORNL, were in the form of polished $1 \mathrm{~cm} \times 2 \mathrm{~cm}$ coupons approximately $1 \mathrm{~mm}$ thick. Substrate samples were cleaned with alcohol and positioned within the vacuum chamber for the plasma deposition and ion bombardment processing. The oil-free system was cryogenically pumped down to a base pressure of about $1 \times 10^{-6}$ Torr before commencing the plasma process. Oxygen gas was admitted to a pressure of 10 to $15 \mathrm{mTorr}$, and the plasma deposition processing carried out as described above. The time required for film growth was usually a few tens of minutes. Note that in this plasma processing the energy added to the sample is small and they are not heated significantly. The samples were then removed from the chamber for characterization and testing. Heating was done in air at temperatures up to $1100^{\circ} \mathrm{C}$. The samples could be inserted into and removed from the hot oven quickly, and the sample heatup and cool-down time was just a few minutes, determined by the thermal capacity of the small coupons. The samples were maintained at full temperature for times varying between 15 minutes and 16 hours. Analysis of film composition was done with Rutherford backscattering spectrometry (RBS) with $1.8 \mathrm{MeV} \mathrm{He}{ }^{+}$ions, and X-Ray diffraction analysis was used to determine the crystallographic phase. Film adhesion was measured with a Sebastian-type pull tester using studs epoxied to the samples and pulled normal to the substrate by known weights; the epoxy failure limit was $\sim 60-70 \mathrm{MPa}$, and this thus determined the instrumental limit.

A number of different samples were prepared and studied of both alumina and chromia and on both silicon carbide and iron aluminide. Several different thicknesses of films were formed, between about $0.2 \mu$ and $1.5 \mu$. We measured: the stoichiometry of the plasma deposited films, both pre- and post-heat treatment; the crystallographic phase of the films produced, pre- and post-heat treatment; and the adhesion of the film to the substrate, pre- and post-heat treatment, and after repetitive thermal cycling. 


\section{Stoichiometry}

RBS analysis showed that the as-prepared samples were usually slightly oxygen-rich, with composition such as for example $\mathrm{Al}_{2} \mathrm{O}_{3.3}$ for an oxygen pressure of $12 \mathrm{mTorr}$. When the oxygen pressure was too high, for example $26 \mathrm{mTorr}$ as in our early work, the films were significantly oxygen rich, with an $\mathrm{Al}_{2} \mathrm{O}_{5}$ composition. The annealed films were, not surprisingly, of good $\mathrm{Al}_{2} \mathrm{O}_{3}$ stoichiometry.

\section{Crystallography}

The as-deposited alumina was typically amorphous with a small amount of $\mathrm{k}-\mathrm{Al}_{2} \mathrm{O}_{3}$. The postheating films were always mostly $\alpha-\mathrm{Al}_{2} \mathrm{O}_{3}$; see Figure 2 .

\section{Adhesion}

The film-substrate adhesion was always good for the as-prepared, pre-heat-treatment films - an adhesion strength as measured with our Sebastian-type pull tester of $\geqq 70 \mathrm{MPa}$, the instrumental limit - for both alumina and chromia films on both $\mathrm{FeAl}$ and $\mathrm{SiC}$ substrates. Post-heattreatment, the adhesion strength of the optimally-prepared films was also good for films of thickness $\leqslant 0.5 \mu$, but films of thickness $\gtrsim 1 \mu$ showed mixed results. Samples were repetitively thermally cycled from room temperature to $1100^{\circ} \mathrm{C}$ through cycles of 15 minutes duration each; heating and cooling time was several minutes only. The film-substrate adhesion both before and after high temperature cycling was excellent, at the $\sim 70 \mathrm{MPa}$ instrumental limit of the pull-tester. More extensive adhesion measurements were made on the mullite films, as described below.

\subsection{MULLITE}

Films of silicon-aluminum oxide were synthesized on polished SiC substrates using the dualplasma approach described above. Control of the stoichiometry of the silicon-aluminum oxide films was achieved by varying the duration of the plasma pulses and the oxygen partial pressure during deposition. The deposition rate of each individual source was determined for all oxygen partial pressures used by measuring the thickness of the deposited films after one thousand pulses of $5 \mathrm{~ms}$ duration each. The individual deposition rates were then used as a basis to prepare films with the desired Al:Si ratios. The films were typically of thickness in the range 0.2 - 2 microns. An edge-on SEM photograph of a typical film mullite film on a silicon carbide substrate is shown in Figure 3.

An advantage of the Mepiiid process is the high degree of atomic mixing achieved; thus here the duration of the pulses used was always below the time required for the formation of monolayers of silica or alumina, and both sources were triggered simultaneously so as to prevent stratification of alumina or silica. A previous attempt to synthesize mullite coatings by depositing alternate layers of silica and alumina by CVD and subsequent annealing failed due to brittleness resulting from the transformation of silica into crystoballite that takes place during the high temperature annealing required to homogenize the multilayer film. Here we wanted to ensure that complete mixing happened during the deposition. 


\section{Composition}

Table 1 shows the composition of several aluminum-silicon oxides films deposited on $\mathrm{SiC}$ under various experimental conditions. The content of each element in the films was determined by Rutherford Backscattering Spectroscopy (RBS) and normalized to the Si content. The accuracy of these measurements is $\pm 15 \%$. Elemental composition of mullite is also included in the table for comparison.

Table 1. Composition of a number of as-deposited mullite films

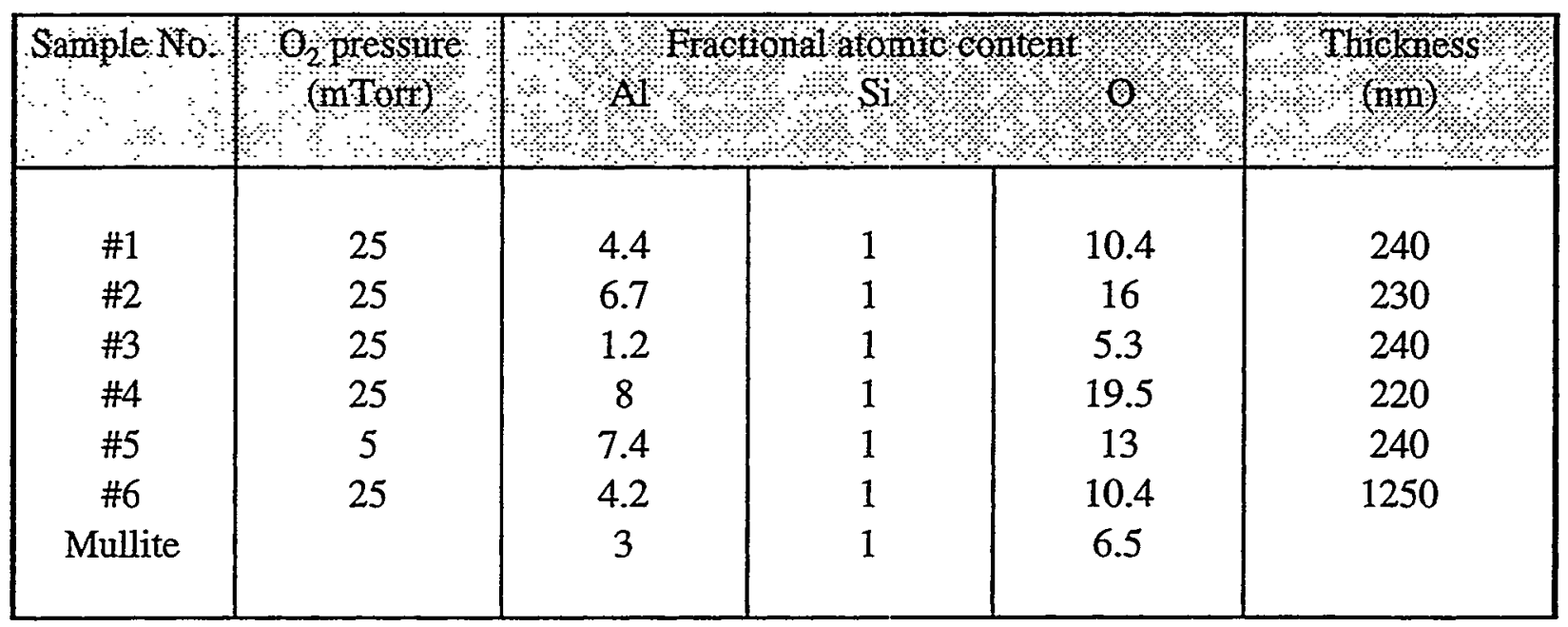

\section{$\underline{\text { X-ray diffraction }}$}

$\mathrm{X}$-ray diffraction indicates that the deposited films were amorphous. No evidence of crystalline structure or phase separation was observed. A feature in the films produced was the high oxygen content when deposition was carried out at $25 \mathrm{mT}$ Torr. An analysis of the compositions shown in Table 1 indicates that films produced at this pressure consist of mixtures of $\mathrm{Al}_{2} \mathrm{O}_{3+\mathrm{x}}$ and $\mathrm{SiO}_{2}+\mathrm{y}$ with a good match being achieved for $\mathrm{x}=2$ and $\mathrm{y}=0 . \quad \mathrm{Al}_{2} \mathrm{O}_{5}$ is not a stable oxide for our deposition conditions, and therefore this composition must be a consequence of oxygen ion bombardment. At lower pressures, oxygen implantation appears to decrease in importance and the films are basically mixtures of $\mathrm{Al}_{2} \mathrm{O}_{3}$ and $\mathrm{SiO}_{2}$.

Annealing of the films at $1100{ }^{\circ} \mathrm{C}$ in air for 2 hours resulted in the formation of crystalline mullite. The alumina-silica binary phase diagram indicates that the only stable phases in the silica-alumina system at the pressures used in this investigation are silica, alumina and mullite. To achieve the mullite stoichiometry, excess oxygen present in the as-deposited films had to be lost to the environment or react with the $\mathrm{SiC}$ substrate to form silicon oxide and/or carbon dioxide. X-ray diffraction indicates mullite as the main crystalline phase after annealing (Figure 4). The low intensity of the diffraction peaks is mostly due to the small film thickness. Another silicon-aluminum oxide known as sillimanite $\left(\mathrm{Al}_{6} \mathrm{Si}_{3} \mathrm{O}_{15}\right)$ can also be fitted to the peaks in the 
diffractogram but was discarded because the ratio of intensities of the diffraction peaks was closer to that expected from mullite. Little difference was observed in the diffraction patterns of the samples \#1 through \#5, indicating that after annealing at $1100{ }^{\circ} \mathrm{C}$, in all cases the main crystalline phase formed was mullite. In the films with very low $\mathrm{Al}$ :Si ratio we were expecting that silicon dioxide would be present as well, and in the films with very high Al:Si ratio, peaks from crystalline alumina were expected. However, neither of these phases, silica or alumina, could be identified from the diffraction patterns of samples \#1 through \#5.

\section{Transmission electron microscopy}

Transmission electron microscopy (TEM) was used to characterize the microstructure of the mullite film after 15 cycles of oxidation. An edge-on bright-field image of an oxidized sample showing the typical morphology of the coated $\mathrm{SiC}$ after oxidation is shown in Figure 5. The film thickness was $0.5 \mu \mathrm{m}$. Figure 5 shows that the mullite film is predominantly crystalline, with grain size approximately the same as the film thickness. This was supported also by transmission electron diffraction and energy dispersive X-ray analysis (EDS) with a microprobe. Between the crystalline mullite and the $\mathrm{SiC}$, there is a layer of amorphous $\mathrm{SiO}_{2}$ (again EDS was used to assess the chemical composition of the layer). Some voids are noticed in the SiC near the $\mathrm{SiO}_{2}$ layer. The presence of these voids can be explained in terms of the oxidation reaction

$$
\mathrm{SiC}+2 \mathrm{O}_{2} \Rightarrow \mathrm{SiO}_{2}+\mathrm{CO}_{2}
$$

Evolution of $\mathrm{CO}_{2}$ or $\mathrm{CO}$ and consumption of $\mathrm{Si}$ into the $\mathrm{SiO}_{2}$ layer could result in voids.

\section{Adhesion}

Adhesion test results for the as-deposited and the annealed films are shown in Table 2. We found that the adhesion strength of the as-deposited films was generally in the range 10-40 $\mathrm{MPa}$, and the post-annealing adhesion strength was equal to or greater than the instrumental limit of $~ 60-70 \mathrm{Mpa}$, i.e. when subjected to a normal pull-test the annealed samples failed at the epoxy and not at the film-substrate interface.

Table 2. Adhesion of as-deposited and annealed mullite films

\begin{tabular}{|c|c|c|c|c|c|c|}
\hline Sample vo & as depo & inariealed & Eraction & C) & 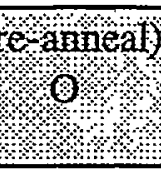 & rticknessis \\
\hline \#1 & 9 & 70 & 4.4 & 1 & 10.4 & 240 \\
\hline \#2 & 38 & 57 & 6.7 & 1 & 16 & 230 \\
\hline \#3 & 31 & 63 & 1.2 & 1 & 5.3 & 240 \\
\hline \#4 & 31 & 57 & 8 & 1 & 19.5 & 220 \\
\hline$\# 5$ & 9 & 65 & 7.4 & 1 & 13 & 240 \\
\hline
\end{tabular}


When the aluminum content of the coating was high (samples \#2, \#4 and \#5) both the asdeposited and the annealed films had a high density of microstructural features that looked like voids or micro-bubbles, as mentioned above. The mechanism of formation of these bubbles is not clear to us, but their concentration seems to be directly related to the deviation of the Al content from the ideal mullite stoichiometric ratio (i.e. the higher the $\mathrm{Al}$ content, the higher the density of voids). Upon annealing, very few voids appear to have broken through the coating, but in places where the film delaminates due to the pull-test, voids were exposed. Subsurface voids were seen to form in the silicon carbide when subjected to high temperature oxidation.

It is clear from the results that annealing of the deposited aluminum-silicon oxides helps greatly to improve the adhesion of the film

\section{Thermal cycling characteristics}

We have investigated the adhesion of the mullite films to silicon carbide when subjected to repeated thermal cycling. Each cycle consisted of heating the samples to $1100^{\circ} \mathrm{C}$ at a rate of 9 ${ }^{\circ} \mathrm{C} / \mathrm{min}$, maintaining the substrate at $1100{ }^{\circ} \mathrm{C}$ for $18 \mathrm{~h}$ in air, and cooling it down at a rate of approximately $4{ }^{\circ} \mathrm{C} / \mathrm{min}$. For the first 5 cycles adhesion was measured after each heat cycle, and after that every 5 or 10 cycles out to a maximum of 40 cycles.

The film-substrate adhesion after thermal cycling was measured using our Sebastian pull tester. However the stress required to debond the mullite film from the SiC substrate often exceeded the maximum strength of the epoxy used; this is the limit of measurement of this technique, about 60-70 MPa. Therefore these measurements can provide only a lower limit for the adhesion strength. This prompted us to use an additional method for characterizing the strength of the bonding between film and substrate.

The method used to measure the interface toughness is based on the indentation method developed by Evans and co-workers [49-51]. This technique involves making microindentations in the surface of the oxide film. The indentation creates a plastically deformed zone immediately beneath the surface. Residual stresses developed in the plastic zone provide the driving force for lateral and radial crack growth [52]. If the interface toughness is lower than the toughness of both the film and the substrate, lateral cracks will develop and propagate along the interface, as indicated in Figure 6. Evans and co-workers have developed fracture mechanics solutions that allow interfacial fracture energies to be calculated from the size of these cracks. In order for the model to be realistic, the depth of the indent should be less than the film thickness.

Due to the small thickness of the mullite films produced here, the indents did perforate through the film, and therefore our estimates of the interface strength should not be taken too quantitatively. One can make arguments that would imply that perforation of the layer would lead either to an underestimate or to an overestimate of the toughness. Figure 7 is an optical micrograph of an indentation mark, with the lateral crack visible. According to the model presented in Figure 6, this determines the end of the delaminated region. We used a load of $1 \mathrm{~kg}$ 
with a Vickers indenter. In spite of these limitations, the test can still be used comparatively, to show trends. The results of both kinds of tests are shown in Table 3 for the thermal cycling tested. The result of the indentation tests in this Table are shown in terms of the radius of the debonded region observed. A value of zero indicates that no crack was observed upon application of the load. Appearance of lateral cracks after cycling the temperature 15 times suggests some weakening of the interface, though still below the detection limit of the Sebastian pull-test.

To illustrate the order of magnitude of the interface strengths determined by the indentation method, we carried out an analysis according to ref. 49 using the model for lateral crack expansion. The following parameters were used for this calculation: crack radius $30 \mu \mathrm{m}$, contact load $1000 \mathrm{~g}$, film thickness $0.2 \mu \mathrm{m}$, film hardness $30 \mathrm{GPa}$. The calculated interfacial fracture resistance was then $\mathrm{K}_{\mathrm{IC} \text {,interface }}=0.8 \mathrm{MPa} \mathrm{m} \mathrm{m}^{1 / 2}$. Despite the uncertainties in this value, it compares highly favorably with the fracture toughness for $\mathrm{SiC}\left(\mathrm{K}_{\mathrm{IC}, \mathrm{SiC}}=4.6 \mathrm{MPa} \mathrm{m}{ }^{1 / 2}\right)$ and mullite [53] $\left(\mathrm{K}_{\mathrm{IC}, \text { mullite }}=2 \mathrm{MPa} \mathrm{m}{ }^{1 / 2}\right)$.

Table 3 Film-substrate adhesion strength as determined by a Sebastian-type pull-test, and lateral crack size as determined by a microindentation test, as a function of number of 24-hour thermal cycles between room temperature and $1100^{\circ} \mathrm{C}$

\begin{tabular}{|c|c|c|}
\hline 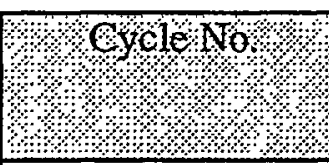 & 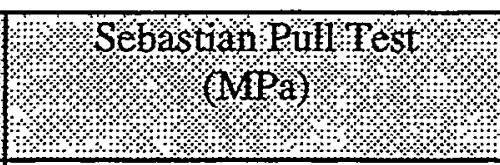 & 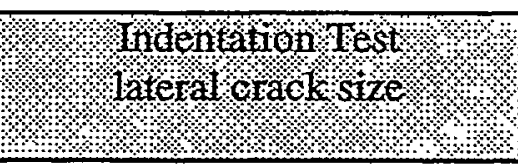 \\
\hline $\begin{array}{c}1 \\
2 \\
3 \\
4 \\
5 \\
10 \\
15 \\
20\end{array}$ & $\begin{array}{l}>70 \\
>70 \\
>70 \\
>70 \\
>70 \\
>70 \\
>70 \\
>70\end{array}$ & $\begin{array}{c}0 \\
0 \\
0 \\
0 \\
0 \\
0 \\
30 \mu \mathrm{m} \\
30 \mu \mathrm{m}\end{array}$ \\
\hline
\end{tabular}

\subsection{YTTRIA AND ZIRCONIA}

The reason for our exploration of yttria-zirconia films is because of their potential use as protective coatings and thermal barriers at elevated temperatures. In the present study, we prepared two types of films of yttrium and zirconium oxides. Both were deposited on (100) silicon substrates at room temperature. We used silicon wafers as substrate material in order to simplify and enhance the compositional analysis with RBS by virtue of the atomically smooth 
silicon surface, it having already been well demonstrated that excellent adhesion of our films to $\mathrm{SiC}$ can be obtained. One set of films consisted of alternating layers of zirconia and yttria in the sequence $\mathrm{ZrO}_{2}-\mathrm{Y}_{2} \mathrm{O}_{3}-\mathrm{ZrO}_{2}-\mathrm{Y}_{2} \mathrm{O}_{3}-\mathrm{ZrO}_{2}-\mathrm{Si}$; these multilayer samples were called $\mathrm{YZO} \# 01$ and $\mathrm{YZO \# 02} \mathrm{(see} \mathrm{Table} 4$ below). A monolithic film was also formed and analyzed; this was called YZO\#03. The approximate thicknesses of the individual layers in the multilayer structure and of the monolithic film are shown in the Table.

Table 4. Structure of some multilayer and monolithic yttria-zirconia films.

\begin{tabular}{|c|c|c|c|c|c|c|}
\hline $\begin{array}{lll} & & \\
& & \\
& & \end{array}$ & $\frac{6}{4+3}$ & 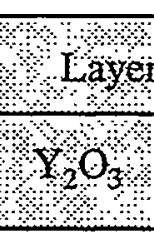 & thenos & $(1 \mathrm{~m})$ & $\frac{1}{4010}$ & 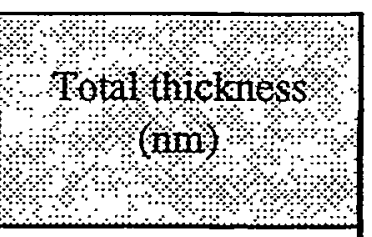 \\
\hline Multilayer YZO\#01 & 100 & 25 & 100 & 25 & 100 & 350 \\
\hline Multilayer YZO\#02 & 100 & 50 & 100 & 50 & 100 & 400 \\
\hline Monolithic YZO\#03 & - & - & - & - & - & 400 \\
\hline
\end{tabular}

$\mathrm{X}$-ray diffraction patterns obtained at glancing angle from the as-deposited samples show only the (311) Si peak with two shoulders. Figure 8 shows a part of the diffraction patterns of the films YZO\#02 (multilayer) and YZO\#03 (monolithic) in the as-deposited condition. The peaks adjacent to the $\mathrm{Si}$ are identified as $\mathrm{Zr}_{3} \mathrm{Y}_{4} \mathrm{O}_{12}$ and $\mathrm{ZrO}_{2}$. Mixed $\mathrm{Y}$ and $\mathrm{Zr}$ oxide is expected to occur, to some extent, in the multilayer films because of the use of high-energy ions for the deposition. The remainder of the diffraction patterns show no features other than a very broad peak with very low intensity, indicating the possibility of other amorphous phases being present.

A noticeable change in structure of these YZO films occurs when they are heat-treated in air at $900{ }^{\circ} \mathrm{C}$ for $45 \mathrm{~min}$. X-ray diffraction patterns of the treated films obtained at a glancing angle of 2 are shown in Figure 9. The formation of crystalline $\mathrm{ZrO}_{2}$ in the YZO\#01 multilayer sample is evident from the diffraction pattern. A limited number of weak reflections that can be related to $\mathrm{Y}_{2} \mathrm{O}_{3}$ were also identified. The diffraction pattern of sample YZO\#02 after similar treatment allows the $\mathrm{Y}_{2} \mathrm{O}_{3}$ peaks to be better resolved, as expected because of the higher volume fraction of $\mathrm{Y}_{2} \mathrm{O}_{3}$ layers. Sample YZO\#03 (monolithic) shows reflections that can be attributed to zirconium-yttrium oxide $\left(\mathrm{Zr}_{3} \mathrm{Y}_{4} \mathrm{O}_{12}\right)$. The proximity of $\mathrm{d}$-spacings and the width of the peaks leave some uncertainty as to the exact phases present in the film.

When these samples are heat treated at $1100^{\circ} \mathrm{Cin}$ air for 5 hours, it becomes obvious that they cannot effectively prevent oxygen diffusion toward the substrate. This is best seen from the RBS data of the samples in the as-deposited condition and after each of the heat treatments. Figure 10 shows the composition depth profiles. Because of the proximity of the atomic masses 
of $\mathrm{Y}$ and $\mathrm{Zr}$ it is difficult to differentiate between the two elements in RBS, and therefore the curves in Figure 10 show the total metal concentration without attempting to discriminate between $\mathrm{Y}$ and $\mathrm{Zr}$. The Si profile is also plotted, to show its oxidation at the highest temperature.

Figure 10(a) and 10(b) show the spectra for the multilayers YZO\#01 and YZO\#02, respectively. Figure 10(c) shows the spectrum of the monolithic YZO\#03 film. All three spectra indicate that after the initial heat treatment there is a decrease in film thickness accompanied by loss of oxygen. The decrease in the width of the $\mathrm{Y}-\mathrm{Zr}$ signal, and a corresponding increase in its height support this conclusion. We have determined in our previous work that when the deposition of oxides is carried out at oxygen partial pressures greater than $20 \mathrm{mTorr}$ the deposited films are oxygen rich. This excess oxygen is thermodynamically unstable, and is lost upon annealing. The RBS spectra in Figure 10 also show that after the $900{ }^{\circ} \mathrm{C}$ treatment no noticeable oxidation of the silicon could be detected. Silicon oxidation, as evidenced by the appearance of the shoulder in the Si signal, was only evident after treatment at $1000^{\circ} \mathrm{C}$. The $\mathrm{RBS}$ spectra indicate that after the high temperature treatment, formation of $\mathrm{SiO}_{2}$ takes place below the yttria-zirconia films by oxygen diffusion towards the $\mathrm{Si}$.

\section{CONCLUSIONS}

We have developed a plasma-based thin film synthesis technique (Metal plasma immersion ion implantation and deposition, Mepiiid) and applied it to form a number of different kinds of high temperature ceramic protective coatings. Films of alumina, chromia, mullite, yttria and zirconia were deposited on substrates of iron aluminide and silicon carbide. Both monolithic films (a single ceramic component) and multilayer films (individual layers of different ceramic materials) were formed. The film deposition is a room-temperature process that results in amorphous or nanocrystalline film structure, with adhesion strength to the metal (iron aluminide) or ceramic (silicon carbide) substrate that is mostly quite strong, at $\sim 70 \mathrm{MPa}$ or greater, our instrumental limit of measurement.

Mullite films were synthesized on silicon carbide by combining plasma streams of $\mathrm{Al}$ and $\mathrm{Si}$ ions produced by vacuum arc plasma guns in a background atmosphere of oxygen. The films are of the stoichiometric $3 \mathrm{Al}_{2} \mathrm{O}_{3} \cdot 2 \mathrm{SiO}_{2}$ composition and fully dense, non-columnar, and smooth. Application of high negative bias voltage to the substrate, i.e. high ion energy, is essential for good adhesion between the film and substrate. The films were tested in a number of different ways having to do with their response to high temperature thermal cycling. The adhesion of the as-deposited mullite is high, increases upon annealing of the film, and remains high over subsequent thermal cycling between ambient and $1100^{\circ} \mathrm{C}$. We found that the films retain their adhesion and quality without any apparent degradation with time, even after a large number of cycles. After repetitive high temperature thermal cycling, the film-substrate adhesion was greater than $\sim 70 \mathrm{Mpa}$, the instrumental limit of measurement, and the interface toughness was approximately $0.8 \mathrm{MPa} \mathrm{m}^{1 / 2}$. 
Yttria-zirconia films with both monolithic or multilayer structures were formed on smooth silicon substrates. The films were initially amorphous following deposition at room temperature, recrystallizing into $\mathrm{Y}_{2} \mathrm{O}_{3}, \mathrm{ZrO}_{2}$ and $\mathrm{Zr}_{3} \mathrm{Y}_{4} \mathrm{O}_{12}$, depending on the starting microstructure, following high temperature annealing. These films do not prevent oxygen transport at temperatures of $1000^{\circ} \mathrm{C}$.

Although the films here were limited in thickness to about 1 micron or so because of dutycycle constraints of the electronics, it is important to recognize that this is not a fundamental limitation of the method. Physical and engineering limitations to scale-up of the Mepiiid process are very high, and one can confidently project that the plasma methods used could be readily developed into a large scale technology for the synthesis of thick films. A cost analysis of the process technology has not been performed, but we note that the related (and simpler and many ways less effective) approach of cathodic-arc PVD is an established industrial technology on a sound competitive footing. Deposition rates are precisely comparable to cathodic-arc PVD, as is also the extent to which the Mepiiid approach is line-of-sight.

\section{ACKNOWLEDGMENTS}

We are indebted to Bob MacGill and Mike Dickinson for their continuous support of the experimental equipment. This work was supported by the U.S. DOE, Office of Advanced Research, Fossil Energy, under subcontract to Oak Ridge National Laboratory ORNL/Sub/94SS109/03, and to the Lawrence Berkeley National Laboratory under Contract Number DEAC03-76SF00098. 


\section{REFERENCES}

1. See, for example, the Proceedings of the annual International Conferences on Metallurgical Coatings and Thin Films (ICMCTF), published as special issues of Thin Solid Films and Surface and Coatings Technology.

2. R.L. Boxman, P. Martin and D. Sanders (eds), Vacuum Arc Science and Technology, Noyes, New York, 1995.

3. D.M. Sanders, J. Vac. Sci. Tech. A7, 2339 (1989).

4. I.G. Brown, in Annual Review of Materials Science, Vol. 28, (Annual Reviews, Inc., Palo Alto, 1998).

5. See, for instance, Ion Implantation and Plasma Assisted Processes, edited by R.F. Hochman, H. Solnick-Legg and K.O. Legg, (ASM, Ohio, 1988).

6. Plasma Processing and Synthesis of Materials, edited by D. Apelian and J. Szekely, Mat. Res. Soc. Symp. Proc. 98, (MRS, Pittsburgh, 1987).

7. See, for instance, the proceedings of the biennial conferences on Ion Implantation Technology, and on Ion Beam Modification of Materials, in Nucl. Intrum. Methods, Part B.

8. M. Iwaki, Critical Rev. in Solid State and Mat. Sci. 15, 473 (1989).

9. G.K. Wolf and W. Ensinger, Nucl. Instr. and Meth. B59/60, 173 (1991).

10. J.R. Conrad, J.L. Radtke, R.A. Dodd, F.J. Worzala and N.C. Tran, J. Appl. Phys. 62, 4591 (1987).

11. See the Proceedings of the International Workshops on Plasma-Based Ion Implantation: J. Vac. Sci. Tech. B12, 815-998 (1994); Surf. Coat. Technol. 85, 1-124 (1996); Surf. Coat. Technol. 93, 158-350 (1997).

12. I.G. Brown. X. Godechot and K.M. Yu, Appl. Phys. Lett. 58, 1392 (1991).

13. I.G. Brown, A. Anders, S. Anders, M.R. Dickinson, I.C. Ivanov, M.A. MacGill, X. Yao and K.M. Yu, Nucl. Instrum. Meth. Phys. Res. B80/81, 1281 (1993).

14. I.G. Brown, in Plasma Synthesis and Processing of Materials, edited by K. Upadhya (pub. TMS, Warrendale, PA, 1993).

15. A. Anders, S. Anders, I.G. Brown and I.C. Ivanov, Mat. Res. Soc. Symp. Proc. 316, 833 (1994).

16. A. Anders, S. Anders, I.G. Brown, M.R. Dickinson and R.A. MacGill, J. Vac. Sci. Tech. B12, 815 (1994).

17. S. Anders, A. Anders, I. Brown, F. Kong and F. McLarnon, Surf. Coat. Technol. $\underline{85}, 75-79$ (1996).

18. I.G. Brown, A. Anders, S. Anders, M.R. Dickinson and R.A. MacGill, J. Vac. Sci. Tech. B12, 823 (1994).

19. M.A. Otooni, I.G. Brown, S. Anders and Z. Wang, Mat. Res. Soc. Symp. Proc. $\underline{396}, 649$ (1996).

20. R.A. MacGill, S. Anders, A. Anders, R.A. Castro, M.R. Dickinson, K.M. Yu and I.G. Brown, Surf. Coat. Technol. 78, 168 (1996).

21. S. Anders, A. Anders, M. Rubin, Z. Wang, S. Raoux, F. Kong and I.G. Brown, Surf. Coat. Technol. 76-77, 167 (1995). 
22. I.G. Brown and Z. Wang, 9th Annual Conference on Fossil Energy Materials, Oak Ridge, TN, May 16-18, 1995, Proceedings of Conference (U.S. Dept. of Energy, Conf-9505204, ORNL/FMP-95/1), p. 239.

23. O.R. Monteiro, Z. Wang, K.-M. Yu, P.Y. Hou, I.G. Brown, B.H. Rabin and G.F. Kessinger, Proc. 10th Annual Conference on Fossil Energy Materials, Knoxville, TN May 14-16, 1996, (Pub. Conf-9605167, ORNL/FMP-96/1, published by US DOE), p. 97.

24. O.R. Monteiro, Z. Wang and I.G. Brown, J. Mat. Res. 12, 2401 (1997).

25. P.Y. Hou, K.B. Alexander, Z. Wang and I.G. Brown, in Elevated Temperature Coatings: Science and Technology II, edited by N.B. Dahotre and J.M. Hampikian (pub. The Minerals, Metals and Materials Society, 1996), p. 187.

26. S. Raoux, I.G. Brown, S. Anders, K.M. Yu and I.C. Ivanov, Mat. Res. Soc. Symp. Proc. 392, 241 (1995).

27. M.S. Chae, M.T. Simnad, M.B. Maple, S. Anders, A. Anders and I.G. Brown, Physica $\underline{C}$ 270, 173 (1996).

28. M.S. Chae, M.B. Maple, M.T. Simnad, S. Anders, A. Anders and I.G. Brown, IEEE Trans. Appl. Supercon. $\underline{5}$, 2011 (1995).

29. O.R. Monteiro, I.G. Brown, R. Sooryakumar and M. Chirita, Mat. Res. Soc. Symp. Proc. 444, 93-98 (1997).

30. G.M. Pharr, D.L. Callahan, S.D. McAdams, T.Y. Tsui, S. Anders, A. Anders, J.W. Ager III, I.G. Brown, C.S. Bhatia, S.R.P. Silva and J. Robertson, Appl. Phys. Letters 68, 779 (1996).

31. S. Anders, A. Anders, I.G. Brown, B. Wei, K. Komvopoulos, J.W. Ager III and K.M. Yu, Surf. Coat. Technol. 68/69. 388 (1994).

32. O.R. Monteiro, M.-P. Delplancke-Ogletree, J.W. Ager and I.G. Brown, Mat. Res. Soc. Symp. Proc. 438, 599 (1997).

33. M.-P. Delplancke-Ogletree, O.R. Monteiro and I.G. Brown, Mat. Res. Soc. Symp. Proc. 438, 639 (1997).

34. S. Anders, D.L. Callahan, G.M. Pharr, T.Y. Tsui and C.S. Bhatia, Surf. Coat. Technol. 94-95, 189 (1997).

35 I.G. Brown, A. Anders, S. Anders, M.R. Dickinson, R.A. MacGill, O.R. Monteiro, E.M. Oks, S. Raoux, Z. Wang and G. Yushkov, Mat. Res. Soc. Symp. Proc. 396, 467 (1996).

36. J.V. Mantese, I.G. Brown, N.W. Cheung and G.A. Collins, in: "Plasma Processing of Advanced Materials", MRS Bulletin 21(8), 52 (1996).

37. J.M. Lafferty (ed.), Vacuum Arcs - Theory and Application, Wiley, New York, 1980.

39. For a most impressive and comprehensive bibliography of the vacuum arc literature see H.C. Miller, A Bibliography and Author Index for Electrical Discharges in Vacuum (1897 -1986), pub. By the General Electric Co., document No. GEPP-TIS-366e (UC-13), March 1988; also published in part in IEEE Trans. Elec. Insul. 25(5),765 (1990) and 26(5), 949 (1991).

39. See the Special Issues on Vacuum Discharge Plasmas in IEEE Trans. Plasma Sci. These issues contain selected papers from the biennial International Symposia on Discharges and Electrical Insulation in Vacuum, usually in the October issues in odd-numbered years. 
40. R.A. MacGill, M.R. Dickinson, A. Anders, O.R. Monteiro and I.G. Brown, Rev. Sci. Instrum. 69, 801 (1998).

41. D.T. Tuma, C.L. Chen and D.K. Davies, J. Appl. Phys. 49, 3821 (1978).

42. J.E. Daalder, Physica 104C, 91 (1981).

43. I.I. Aksenov, A.N. Belokhvostikov, V.G. Padalka, N.S. Repalov and V.M. Khoroshikh, Plasma Physics and Controlled Fusion 28, 761 (1986).

44. A. Anders, S. Anders and I.G. Brown, Plasma Sources Sci. \& Technol. 4 , 1 (1995).

45. S. Anders, A. Anders and I.G. Brown, J. Appl. Phys. 75, 4895 (1994).

46. I.G. Brown and X. Godechot, IEEE Trans. Plasma Sci. PS-19. 713 (1991).

47. I.G. Brown, Rev. Sci. Instrum. 10, 3061 (1994).

48. S. Anders, S. Raoux, K. Krishnan, R.A. MacGill and I.G. Brown, J. Appl. Phys. $\underline{79}, 6785$ (1996).

49. S.S. Chiang, D.B. Marshall and A.G. Evans in Surfaces and Interfaces in Ceramic and Ceramic-Metal Systems, edited by J. Pask and A.G. Evans, Plenum Press, New York, 1981; p. 603.

50. D.B. Marshall, B.R. Lawn and A.G. Evans, J. Am. Ceram. Soc. 65, 561 (1982).

51. D.B. Evans and A.G. Evans, J. Appl. Phys. 24, 209 (1984).

52. P.Y. Hou and A. Atkinson, Mater. at High Temp. 12, 119 (1994).

53. R. Torrecillas, G. Fantozzi, S. de Aza and J.S. Moya, Acta Mater. 45, 897 (1997). 


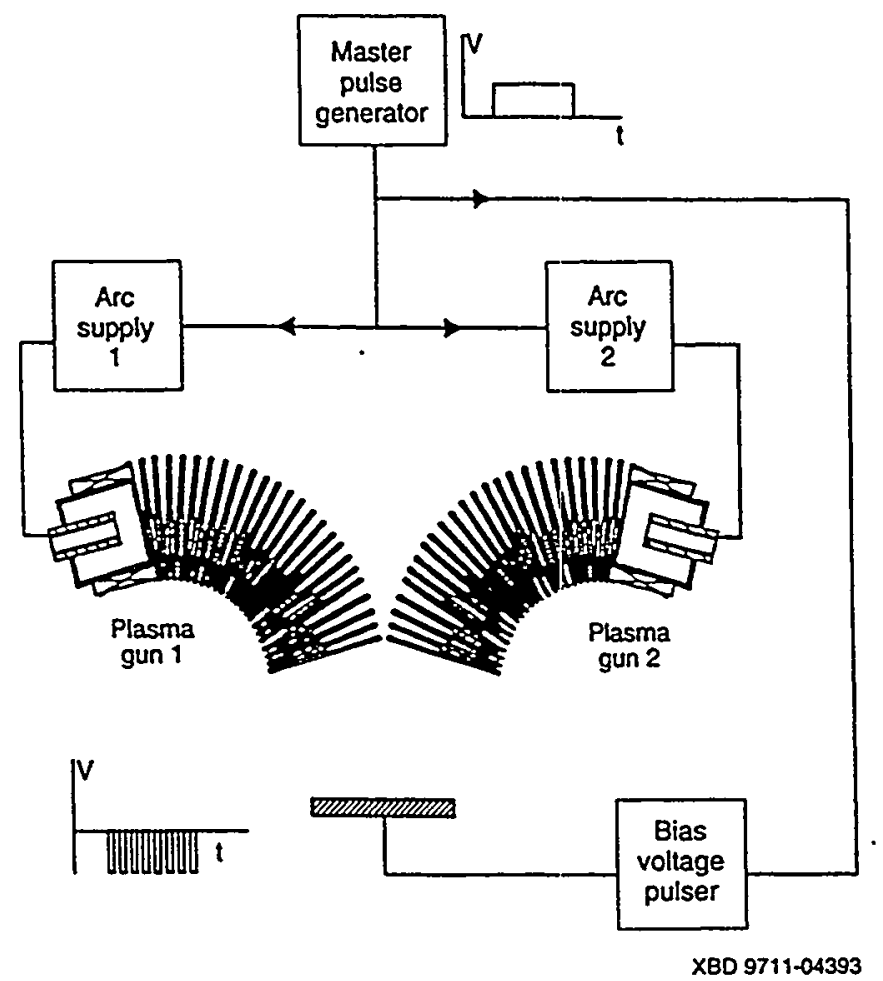

Fig. 1 Simplified schematic of the dual-plasma configuration used to form two-component films.

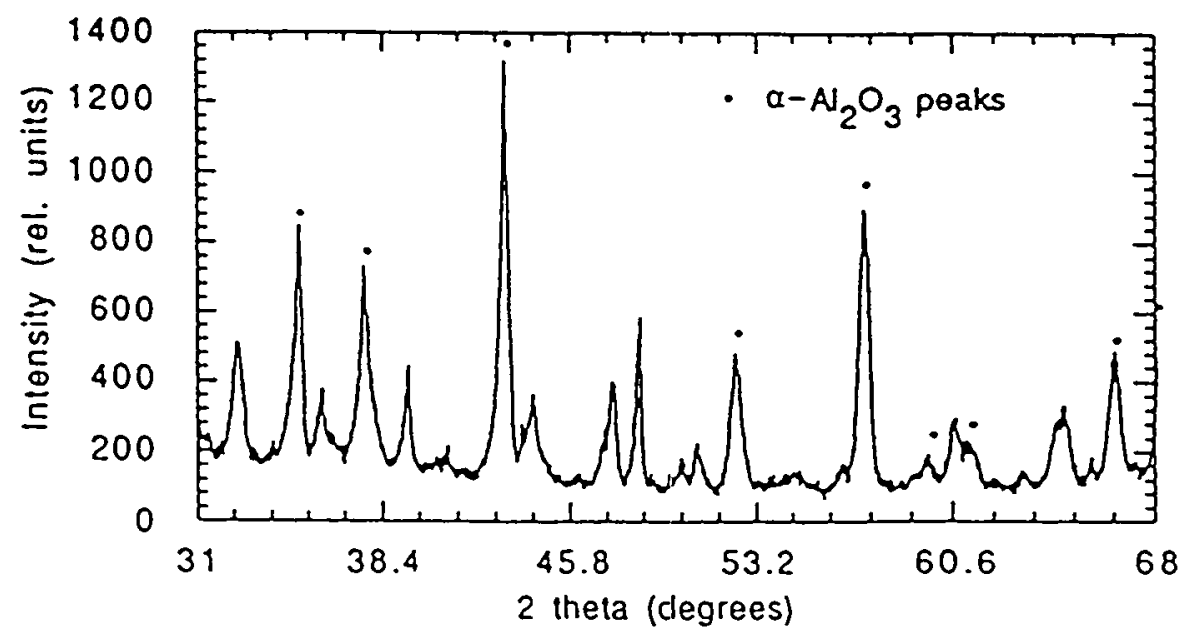

Fig. 2 X-ray diffraction spectrum for an alumina film, after heating at $1000{ }^{\circ} \mathrm{C}$ for 16 hours, indicating mostly $\alpha-\mathrm{Al}_{2} \mathrm{O}_{3}$ phase. Film thickness $0.5 \mu$; on $\mathrm{FeAl}$ substrate. 


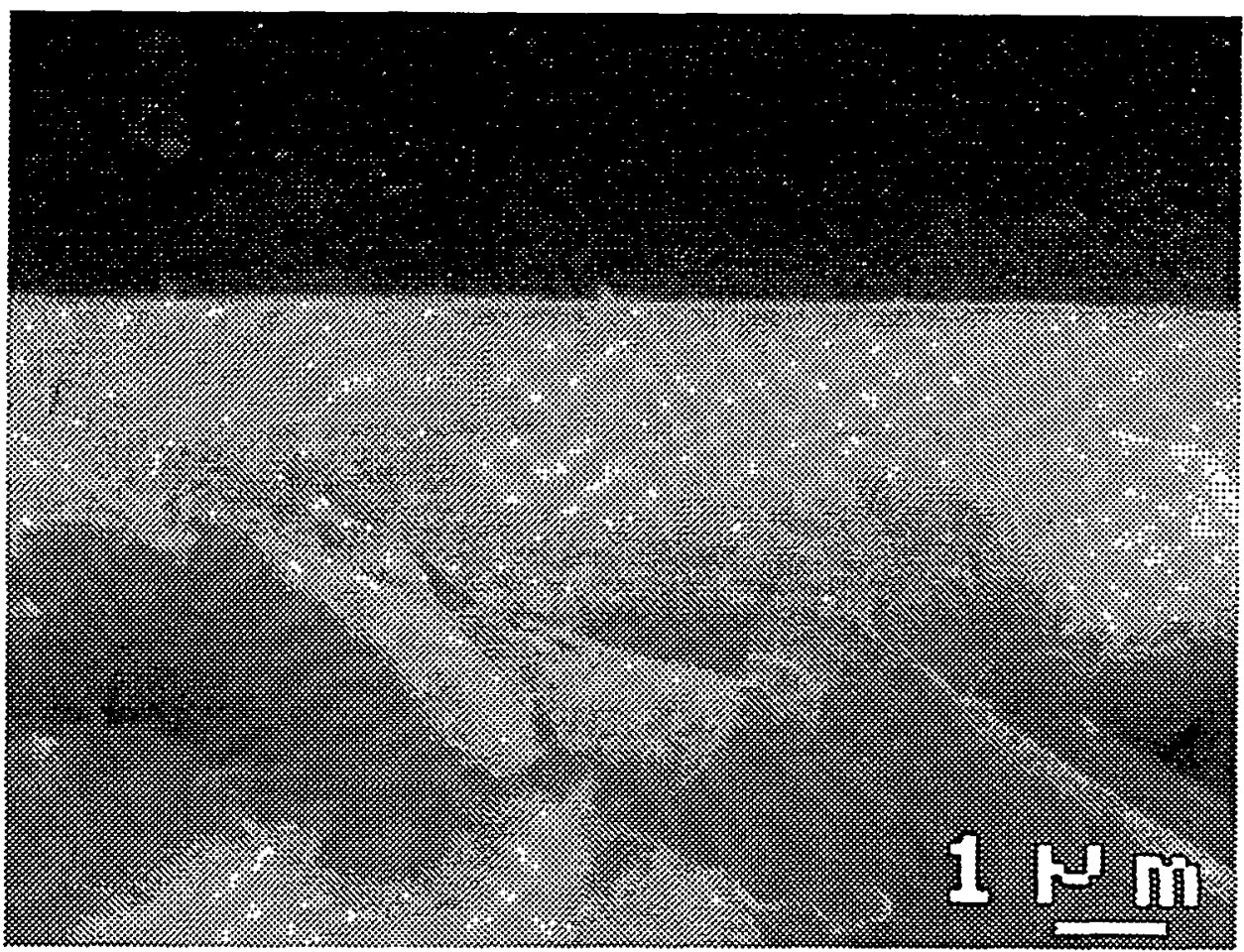

Fig. 3 Edge-on scanning electron microscope photograph of a thin film of mullite formed by the dual-source Mepiid process on a silicon carbide substrate. Aluminum and silicon plasmas were combined in the appropriate proportions in a low pressure background of oxygen to form the $3 \mathrm{Al}_{2} \mathrm{O}_{3} .2 \mathrm{SiO}_{2}$ mullite composition 


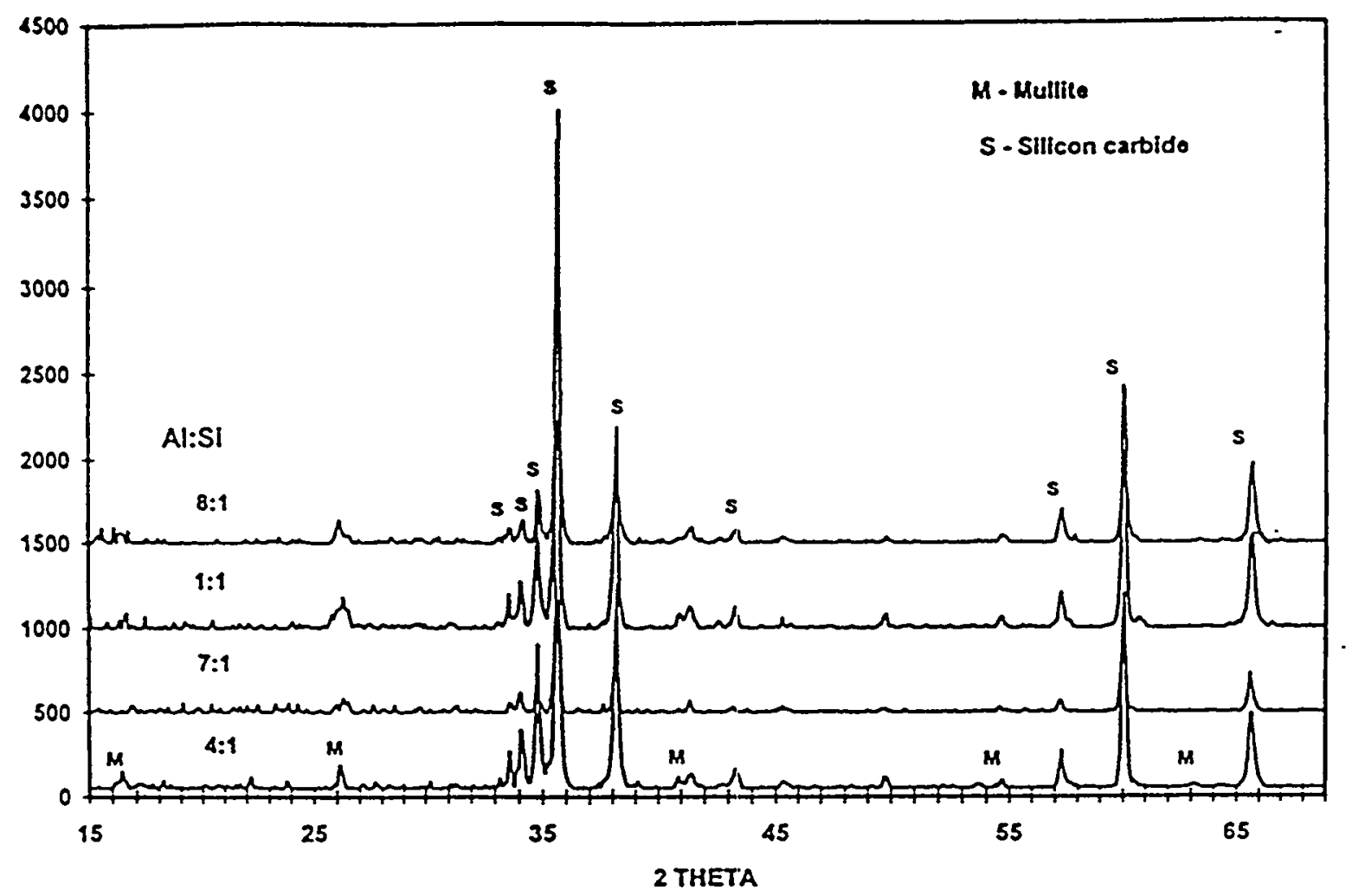

Fig. 4. X-ray diffraction pattern of mullite-coated silicon carbide samples (with composition as shown) annealed at $1100^{\circ} \mathrm{C}$ for 2 hours in air. 

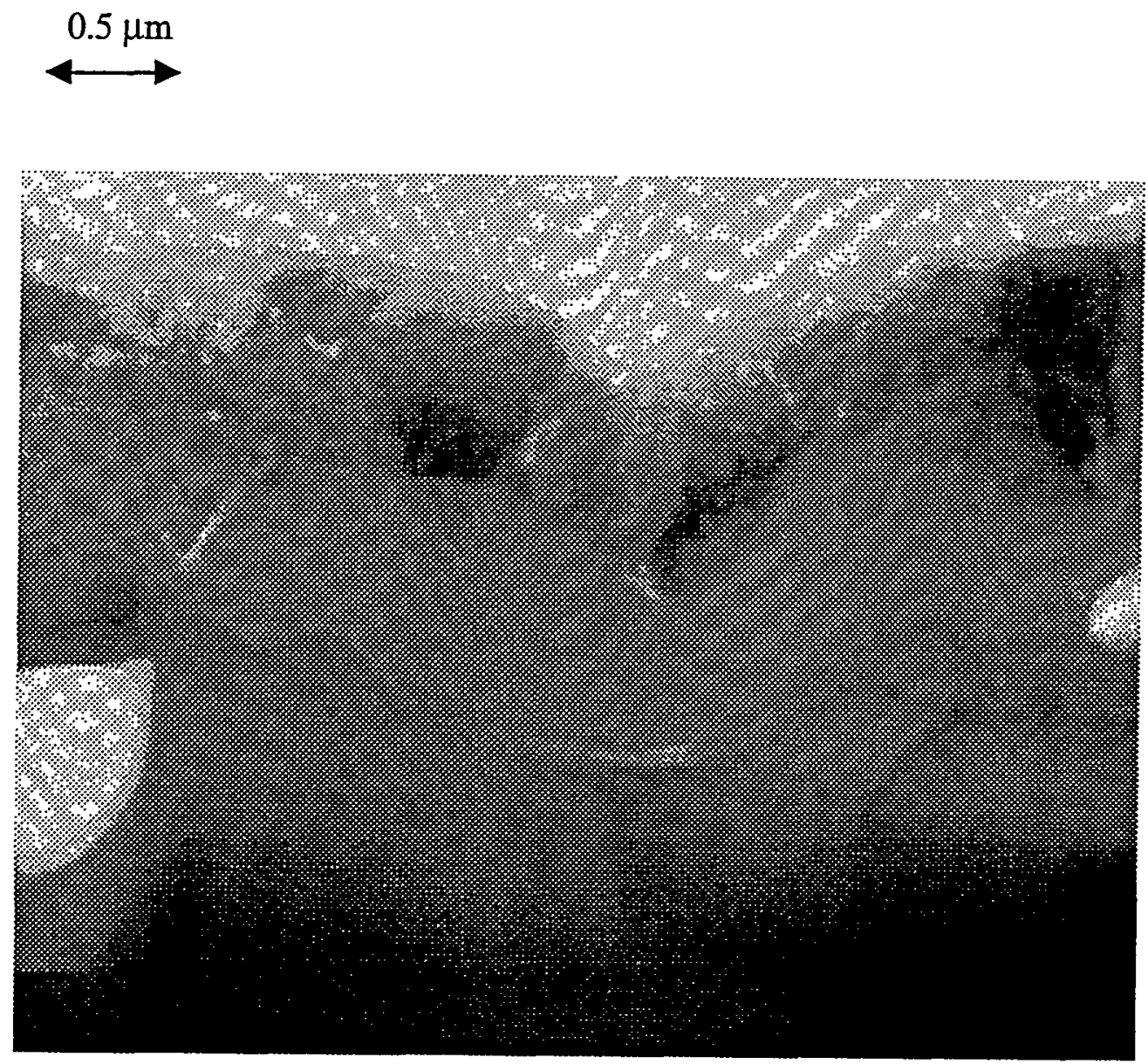

Fig. 5 Bright-field image of a mullite coated $\mathrm{SiC}$ after 15 oxidation cycles at $1100^{\circ} \mathrm{C}$. The topmost layer is crystalline mullite, the intermediate layer is amorphous $\mathrm{SiO}_{2}$. 


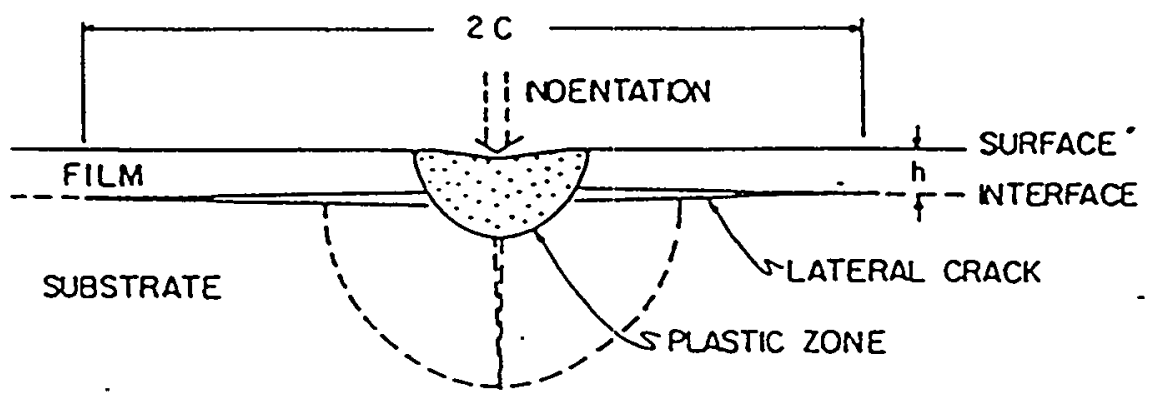

Fig. 6 Schematic of an indentation made on a film-substrate sample, showing the lateral crack propagating preferentially along the interface.

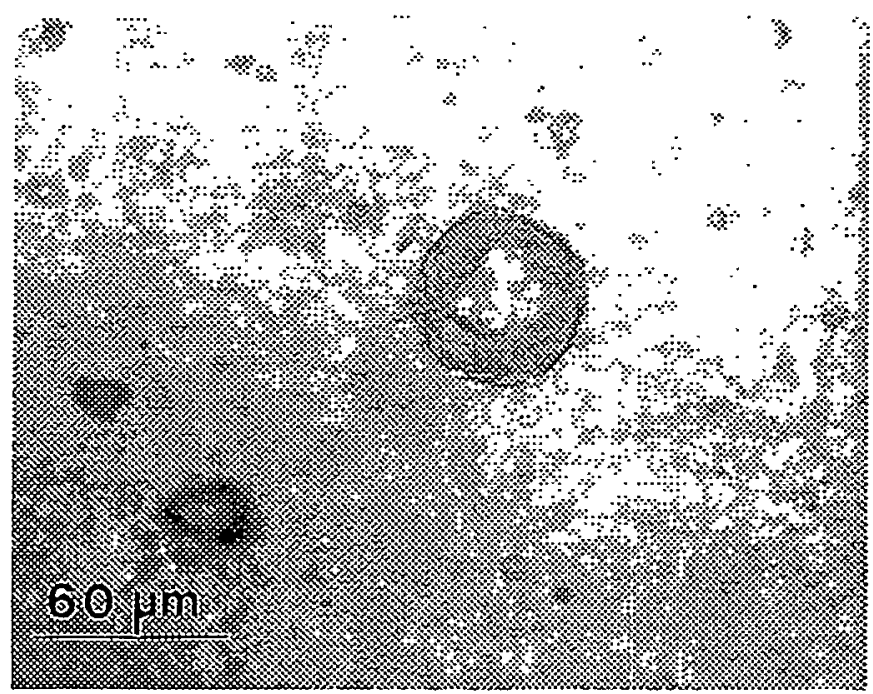

Fig. 7 Optical micrograph of a Vickers indent on a mullite film on a SiC substrate. Indentation load was $1000 \mathrm{~g}$. 

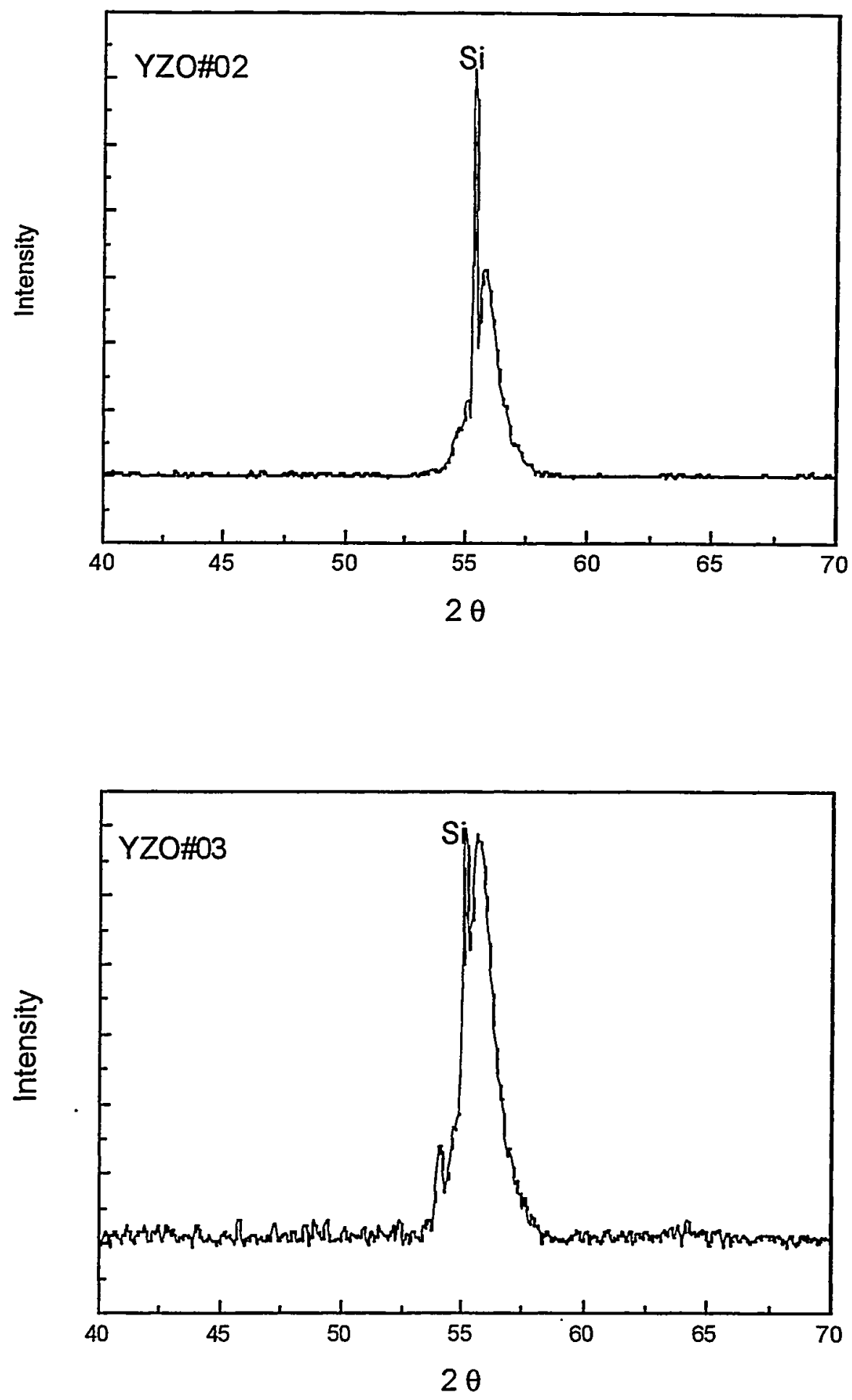

Fig. 8 X-ray diffraction patterns of samples YZO\#02 and YZO\#03 in the as-deposited condition. 

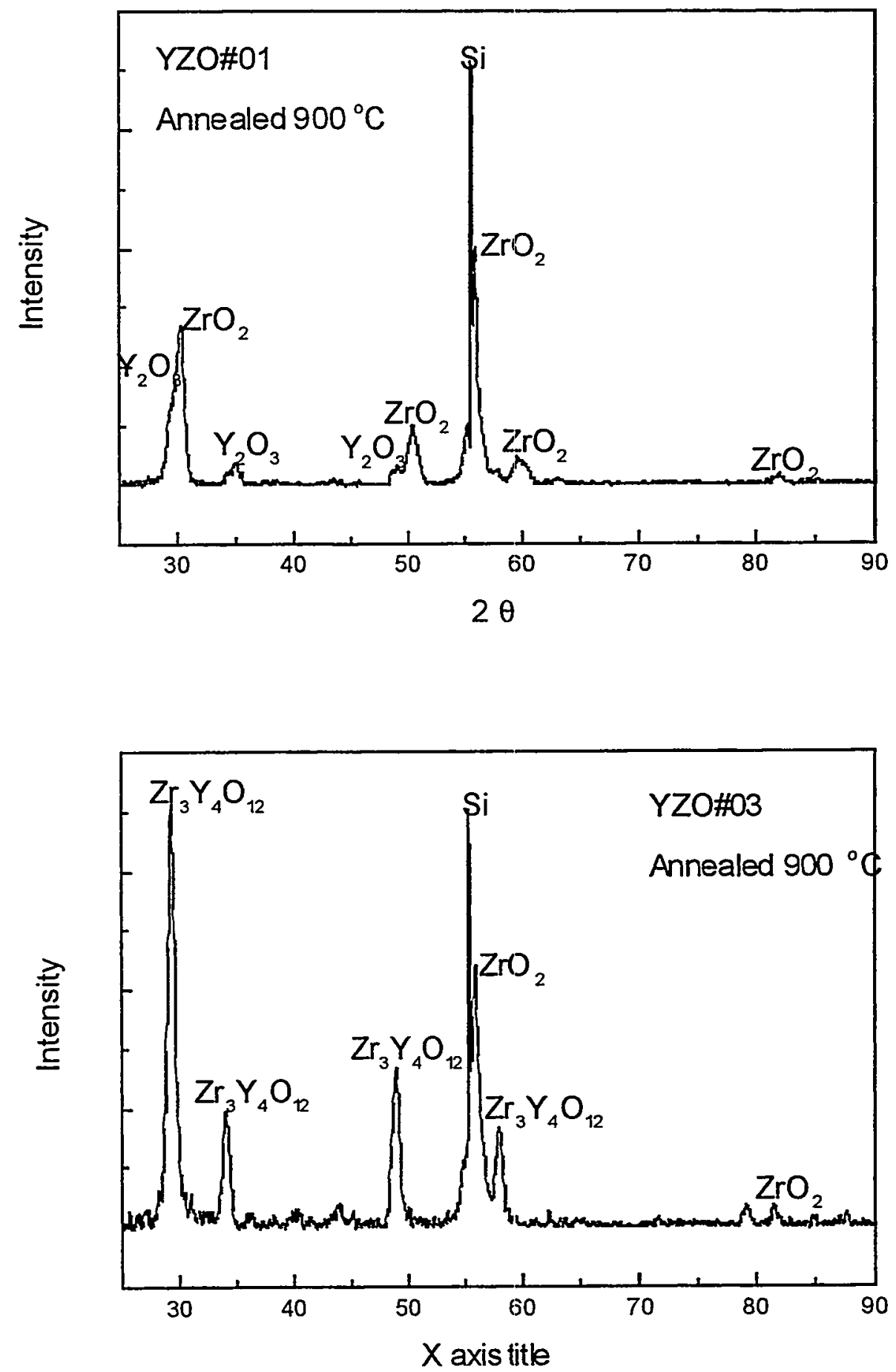

Fig. 9 X-ray diffraction pattern of samples YZO\#01 and YZO\#03 after annealing in air at $900^{\circ} \mathrm{C}$ for 45 minutes. 


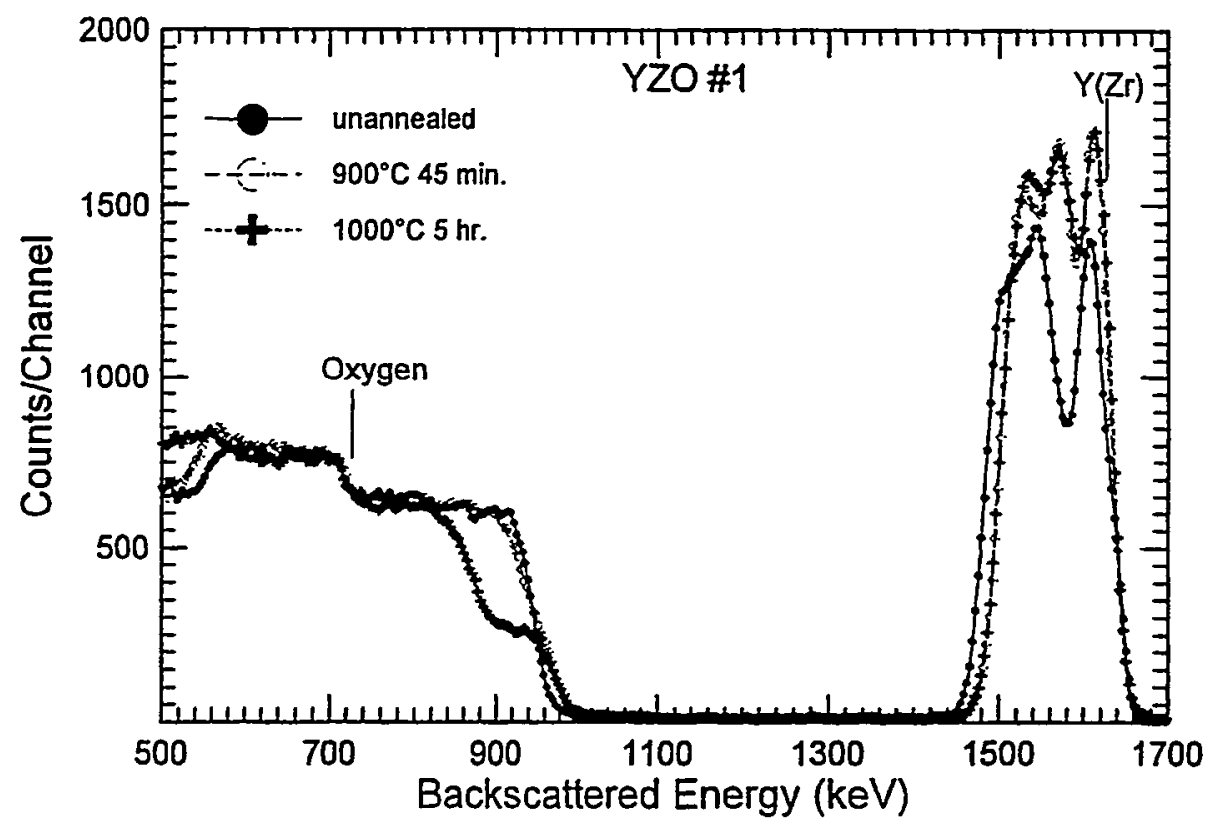

(a)

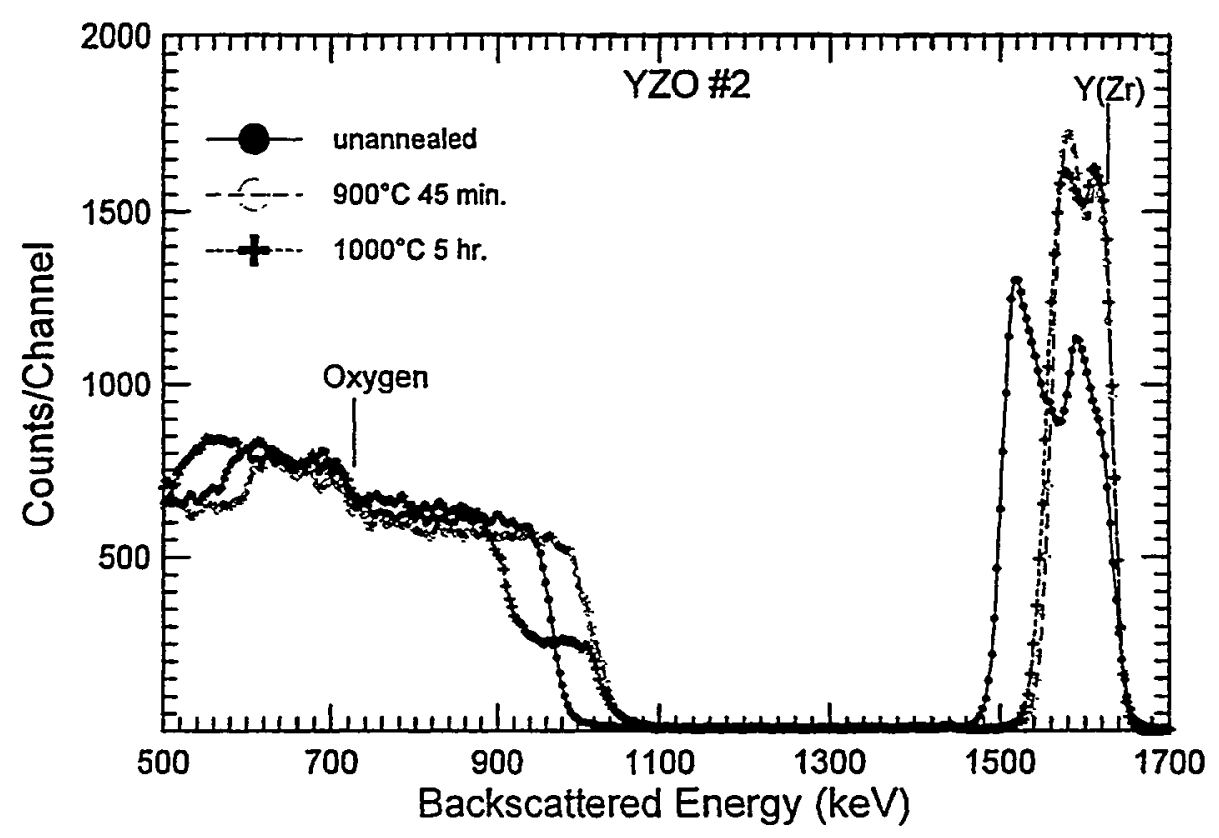

(b) 


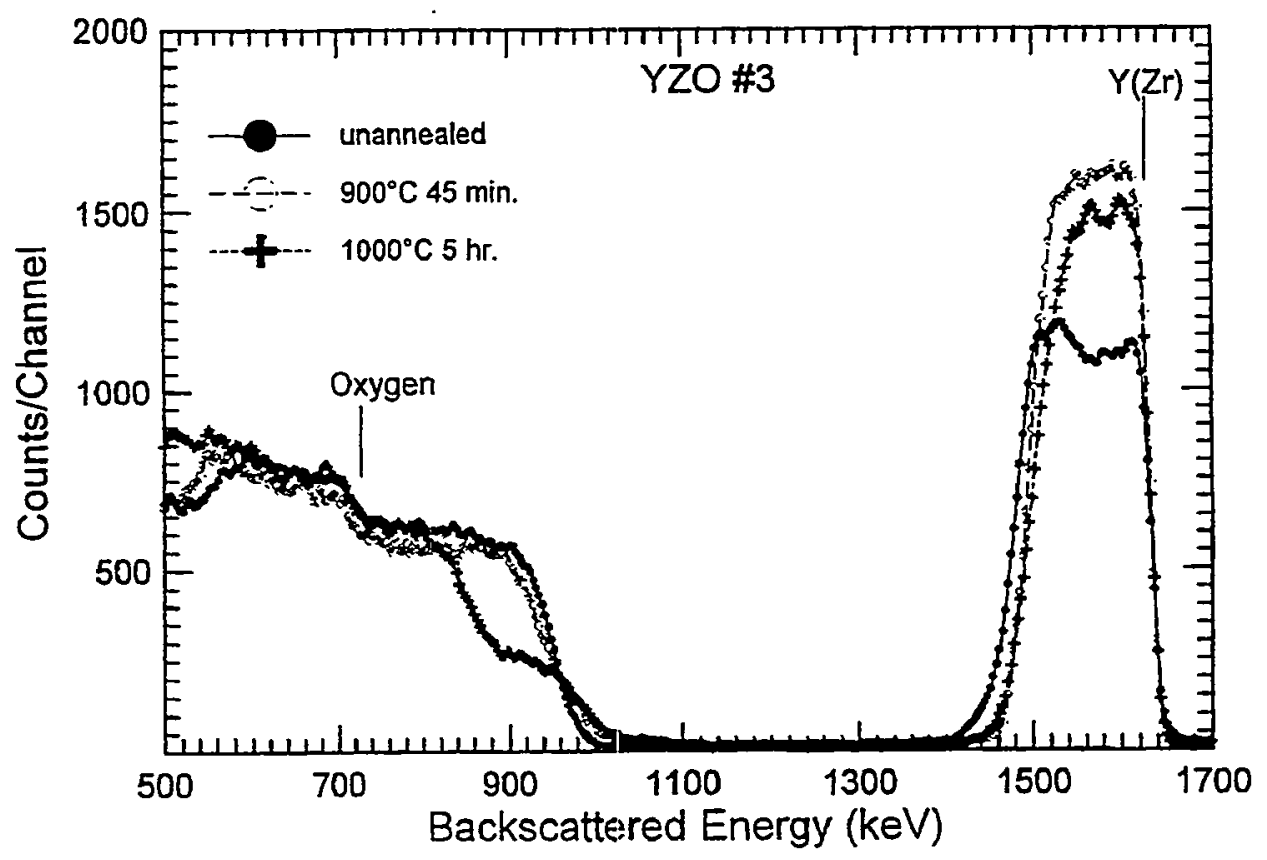

(c)

Fig. 10 RBS spectra of samples (a) YZO\#01, (b) YZO\#02, and (c) YZO\#03, in the as-deposited condition and after oxidation at $900^{\circ} \mathrm{C}$ and $1000^{\circ} \mathrm{C}$. 
3M COMPANY

Ceramic Materials Department

201-4N-01 3M Center,

St. Paul, MN 55144

M. A. Leitheiser

AIR PRODUCTS AND CHEMICALS

P.O. Box 538

Allentown, PA 18105

S. W. Dean

\author{
ALLISON GAS TURBINE DIVISION \\ P.O. Box 420 \\ Indianapolis, IN 46206-0420 \\ P. Khandelwal (Speed Code W-5) \\ R. A. Wenglarz (Speed Code W-16)
}

AMA RESEARCH \& DEVELOPMENT CENTER

5950 McIntyre Street

Golden, CO 80403

T. B. Cox

\author{
ARGONNE NATIONAL LABORATORY \\ 9700 S. Cass Avenue \\ Argonne, IL 60439 \\ W. A. Ellingson \\ J. P. Singh \\ BABCOCK \& WILCOX \\ Domestic Fossil Operations \\ 20 South Van Buren Avenue \\ Barberton, $\mathrm{OH} 44023$ \\ M. Gold \\ BRITTSH COAL CORPORATION \\ Coal Technology Development Division \\ Stoke Orchard, Cheltenham \\ Glocestershire, England GL52 4ZG \\ J. Oakey \\ DOE \\ DOE OAK RIDGE OPERATIONS \\ P. O. Box 2008 \\ Building 4500N, MS 6269 \\ Oak Ridge, TN 37831 \\ M. H. Rawlins
}

\section{DOE}

OFFICE OF BASIC ENERGY SCIENCES

Materials Sciences Division

ER-131

19901 Germantown Road

Germantown, MD 20874-1290

H. M. Kerch

DOE

FEDERAL ENERGY TECHNOLOGY CENTER

3610 Collins Ferry Road

P.O. Box 880

Morgantown, WV 26507-0880

R. C. Bedick

D. C. Cicero

F. W. Crouse, Jr.

R. A. Dennis

N. T. Holcombe

W. J. Huber

T. J. McMahon

J. E. Notestein

DOE

FEDERAL ENERGY TECHNOLOGY CENTER 626 Cochrans Mill Road

P.O. Box 10940

Pittsburgh, PA 15236-0940

A. L. Baldwin

G. V. McGurl

U. Rao

L. A. Ruth

T. M. Torkos

DOE

OFFICE OF FOSSIL ENERGY

FE-72

19901 Germantown Road

Germantown, MD 20874-1290

F. M. Glaser

DOE

OFFICE OF VEHICLE AND ENERGY R\&D

CE-151 Forrestal Building

Washington, DC 20585

R. B. Schulz 
ELECTRIC POWER RESEARCH INSTITUTE

P.O. Box 10412

3412 Hillview Avenue

Palo Alto, CA 94303

W. T. Bakker

J. Stringer

EUROPEAN COMMUNITIES JOINT RESEARCH CENTRE

Petten Establishment

P.O. Box 2

1755 ZG Petten

The Netherlands

M. Van de Voorde

IDAHO NATIONAL ENGINEERING \& ENVIRONMENTAL LABORATORY

P. O. Box 1625

Idaho Falls, ID 83415

B. H. Rabin

\author{
LAWRENCE LIVERMORE NATIONAL \\ LABORATORY \\ P.O. Box 808, L-325 \\ Livermore, CA 94550 \\ W. A. Steele
}

NATIONAL MATERIALS ADVISORY BOARD

National Research Council

2101 Constitution Avenue

Washington, DC 20418

K. M. Zwilsky

OAK RIDGE NATIONAL LABORATORY

P.O. Box 2008

Oak Ridge, TN 37831

T. M. Besmann

P. T. Carlson

J. M. Crigger (4 copies)

R. R. Judkins

R. A. Lowden

D. P. Stinton

V. M. Vaubert

OFFICE OF NAVAL RESEARCH

Code 431, 800 N. Quincy Street

Arlington, VA 22217

S. G. Fishman
SHEILL DEVELOPMENT COMPANY

WTC R-1371

P.O. Box 1380

Houston, TX 77251-1380

W. C. Fort

TENNNESSEE VALLEY AUTHORITY

Energy Demonstration \& Technology

MR2N58A

Chattanooga, TN 37402-2801

C. M. Huang

THE JOHNS HOPKINS UNIVERSITY

Materials Science \& Engineering

Maryland Hall

Baltimore, MD 21218

R. E. Green, Jr.

THE MATERIALS PROPERTIES COUNCIL, INC.

United Engineering Center

345 E. Forty-Seventh Street

New York, NY 10017

M. Prager

THE NORTON COMPANY

High Performance Ceramics Division

Goddard Road

Northborough, MA 01532-1545

N. Corbin

\section{UNION CARBIDE CORPORATION}

Linde Division

P.O. Box 44

175 East Park Drive

Tonawanda, NY 14151-0044

Harry Cheung

UNITED TECHNOLOGIES RESEARCH CENTER

MS 24, Silver Lane

East Hartford, CT 06108

K. M. Prewo

UNIVERSITY OF TENNESSEE

Dept of Materials Science and Engineering

Knoxville, TN 37996-2200

P. K. Liaw 
UNIVERSITY OF WASHINGTON

Department of Materials Science and

Engineering

101 Wilson, FB-10

Seattle, WA 98195

T. G. Stoebe

VIRGINIA POLYTECHNIC INSTITUTE \& STATE

UNIVERSITY

Department of Materials Engineering

Blackburg, VA 24601

K. L. Reifsnider

WESTERN RESEARCH INSTITUTE

365 N. 9th Street

P.O. Box 3395

University Station

Laramie, WY 82071

V. K. Sethi

WESTINGHOUSE ELECTRIC CORPORATION

Research and Development Center

1310 Beulah Road

Pittsburgh, PA 15235-5098

S. C. Singhal 